\title{
Silica reinforced triblock copolymer gels
}

\author{
E. Theunissen ${ }^{a}$, N. Overbergh ${ }^{a}$, H. Reynaers ${ }^{a}$, S. Antoun ${ }^{b}$, R. Jérôme ${ }^{b}$ and K. Mortensen ${ }^{c}$ \\ ${ }^{a}$ Laboratorium voor Macromoleculaire Structuurchemie, Departement Scheikunde, Katholieke Universiteit \\ Leuven, Celestijnenlaan 200F, B-3001, Leuven-Heverlee, Belgium \\ ${ }^{\mathrm{b}}$ Center for Education and Research on Macromolecules (CERM), University of Liège, Sart-Tilman, B6, B- \\ 4000, Liège, Belgium \\ ${ }^{c}$ Danish Polymer Centre, Risø National Laboratory, 4000, Roskilde, Denmark
}

\begin{abstract}
The effect of silica and polymer coated silica particles as reinforcing agents on the structural and mechanical properties of polystyrene-poly(ethylene/butylene)-polystyrene (PS-PEB-PS) triblock gel has been investigated. Different types of chemically modified silica have been compared in order to evaluate the influence of the compatibility between gel and filler.

Time-resolved SANS and small-angle X-ray scattering (SAXS) shows that the presence of silica particles affects the ordering of the polystyrene domains during gelsetting. The scattering pattern of silica-reinforced gels reveals strong scattering at very low $q$, but no structure and formfactor information. However, on heating above the viscoelastic to plastic transition, the 'typical' scattering pattern of the copolymer gel builds-up. All reinforced gels are strengthened by the addition of the reinforcing agent. The transitions from a viscoelastic rubber to a plastic fluid and from a plastic fluid to a viscoelastic liquid are shifted to more elevated temperatures when silica is added to the triblock copolymer gel.
\end{abstract}

Keywords: Author Keywords: Block copolymer; Silica reinforced gel; Morphological study

\section{Introduction}

Thermoplastic elastomeric gels are a fascinating and commercial important class of polymeric materials. Of special interest are the linear ABA triblock copolymer gels, which combine softness and elasticity in a wide temperature range [1-35].

Small-angle scattering studies [1-2; 21-26] and TEM studies [27-29] proved that ABA-block copolymers, when mixed with a solvent or an extender oil selective for the midblock, but incompatible with the outerblocks, aggregate into microdomains. This results in a nanophase separation between the endblocks and the matrix, containing the (dissolved) midblock and the solvent. The midblocks form either loops or bridges between micelles, depending on whether the polymer endblocks are located in the same nanophase or not. Two models were found to be useful to describe the scattering patterns of the triblock copolymer gels: a hard sphere liquid model (Percus-Yevick model) or a local co-ordination model [22-23]. The first model represents a liquid of effective hard-sphere cores surrounded by a (fictitious) hard-sphere shell. The co-ordination model starts from crystalline order in a limited region of space, involving distortions of the interdomain distances.

Rheological studies [30-34] of polystyrene-poly(ethylene/butylene)-polystyrene (PS-PEB-PS) triblock copolymer gels showed that the gels are in a rubber-like viscoelastic state at ambient temperature, which means that the polystyrene domains act as permanent physical crosslinks. Above the glass transition temperature $\left(T_{\mathrm{g}}\right)$ of the PS nanodomains, there is a change from a rubbery gel to a plastic fluid. Indeed, the PS blocks can be pulled out from the original polystyrene domains and migrate to other ones through the rubbery phase. Kleppinger et al. [24-26] showed that in the plastic fluid temperature regime the domains are organised according to a bodycentred cubic lattice. Further increase of temperature results in a viscoelastic liquid and polystyrene migration from one domain to another takes place by thermal motions.

In order to broaden the application field of PS-PEB-PS (and PS-PIP-PS) triblock copolymer gels, a general strategy relies on the chemical modification of the constitutive blocks, which allows to systematically tune the thermodynamics of the system. Changing the chemical nature of one or both the component blocks can have dramatic effects on the self-assembly of the resultant material. Modification of the polydiene block in polystyrene-polydiene-polystyrene block copolymers has received much attention [35-41], including the 
selective hydrogenation of the midblock. Because the transition temperature from a rubbery gel to a plastic fluid $\left(T_{\mathrm{P}}\right)$ is too low for many applications, polystyrene has been either replaced by a higher $T_{\mathrm{g}}$ block [42-45] or chemically modified [46-47]. An alternative strategy is the physical modification of one phase of the gel by appropriate additives. For instance, $T_{\mathrm{g}}$ of the PS domains has been increased by addition of miscible high $T_{\mathrm{g}}$ polyphenylene oxide (PPO) [48].

In this work, silica is proposed as a reinforcing agent of the rubbery matrix of PS-PEB-PS gels. Due to the hydrophobic-hydrophilic interactions between the various silica particles and polystyrene blocks, silica will reinforce the rubbery matrix of the gel. A number of advantages are expected from this modification, i.e. a higher plateau modulus and a lower thermal expansion coefficient. The compatibility of the silica particles within the rubbery matrix plays a key-role in the effectiveness of the system, but appears to be rather low in the case of hydrophilic silica. In order to favour the interactions of silica with the gel matrix and thus to improve the mechanical and thermal performances of the gel, various types of silica have been used and the silica surface has been modified by grafted oligomer or polymer chains, including chains bearing moisture-curable groups, thus able to form additional crosslinks after the gel setting.

\section{Experimental procedures}

\subsection{Materials}

\subsubsection{Gels}

Polystyrene- $b$-poly(ethylene-co-butylene)- $b$-polystyrene triblock copolymers (SEBS) with average molar mass, polystyrene content and polydispersity of $92.000,26 \%$ and 1.1, respectively (Kraton G1650, Shell, Louvain-laNeuve, Belgium) was dissolved in the Fina oil A360, which consists of a mixture of aliphatic and alicyclic hydrocarbons with an average molar mass of ca. 400 . The mixture was heated at $160-180{ }^{\circ} \mathrm{C}$ under vacuum, until a clear solution was formed. Silica was then added and mixed for 10 additional minutes under vacuum, followed by quenching to room temperature. Transparent and highly elastic gels were accordingly prepared that contained $18.5 \mathrm{wt} \%$ of SEBS and $2.2 \mathrm{wt} \%$ of silica. Neat gels (thus without silica) were also prepared with the same composition (i.e., $18.5 \mathrm{wt} \%$ of SEBS).

\subsubsection{Silica}

Types of silica. Different types of silica were used, including silica with hydroxyl groups on the surface $\left(\mathrm{SiO}_{2}-\right.$ $\mathrm{OH}$, H5 from Cabot Corp., powder) and silica modified by hydrophobic chains, i.e. hexamethylene groups ( $\mathrm{SiO}_{2}$-hexyl, TS530 from Cabot Corp.), polydimethylsiloxane (PDMS) chains ( $\mathrm{SiO}_{2}-\mathrm{PDMS}$, TS720 from Cabot Corp.), polybutadiene chains (PBd-TEOS-SiO 2$)$ and poly(dodecylmethacrylate (DMA)-co-styrene-comethacryloxy-propyltrimethoxysilane (SiMA)) chains $\left(\mathrm{SiO}_{2}-\mathrm{DMA} / \mathrm{SiMA}\right)$, respectively.

The average diameter of the primary $\mathrm{SiO}_{2}$ particles was $7 \mathrm{~nm}$, and the aggregates were of roughly $100 \mathrm{~nm}$ diameter.

Synthesis of PBd-TEOS-SiO $2 . \alpha$-Hydroxy polybutadiene (PBd-OH) with an average molar mass of 3700 (liquid Kraton L1203) was reacted with tetraethyl orthosilicate (TEOS) in the presence of dibutyltin dilaurate as a catalyst $(1 \mathrm{wt} \%$ with respect to $\mathrm{PBd}-\mathrm{OH})$, the $(\mathrm{PBd}-\mathrm{OH}) /(\mathrm{TEOS})$ molar ratio being $1: 1$. The reaction was carried out at room temperature for 2 days, followed by elimination of the ethanol subproduct at $50{ }^{\circ} \mathrm{C}$ under vacuum. ${ }^{1} \mathrm{H}-\mathrm{NMR}$ analysis showed a peak characteristic of the $\mathrm{CH}_{2}-\mathrm{O}-\mathrm{Si}$ protons at $3.55 \mathrm{ppm}$, which confirmed the successful chain end-capping. The PBd-TEOS chains were then reacted with the $\mathrm{SiO}_{2}-\mathrm{OH}$ silica in the presence of $50 \mathrm{wt} \%$ of Fina oil in order to get a homogeneous mixture with low viscosity.

Synthesis of silica coated with DMA/SiMA copolymer. Dodecylmethacrylate (DMA) (Aldrich) and styrene were dried over calcium hydride, distilled under reduced pressure and stored under nitrogen at $-20{ }^{\circ} \mathrm{C}$. Methacryloxypropyltrimethoxysilane (SiMA) (Aldrich) was used without further purification.

First step: synthesis of silica coated with $\mathrm{SiMA}$. $\mathrm{SiO}_{2}-\mathrm{OH}$ silica was dispersed in dry toluene and allowed to react with methacryloxy-propyltrimethoxysilane (SiMA) at $25^{\circ} \mathrm{C}$ for one night in the presence of $5 \mathrm{~mol} \%$ hexamethylenediamine, with respect to SiMA. This additive acts as a catalyst for SiOR condensation into SiOSi at the surface of the silica particle. After filtration, the reaction product (Silica-SiMA) was washed with toluene 
and dried under vacuum at $30{ }^{\circ} \mathrm{C}$. ${ }^{1} \mathrm{H}-\mathrm{NMR}$ analysis showed the resonances characteristic of the methacrylic double bond at 6.05 and $5.54 \mathrm{ppm}$, respectively.

Second step: copolymerisation of DMA-SiMA with SiMA-silica. A mixture (96:4 wt\%) of DMA/SiMA monomers ( $1 \mathrm{~g})$ and silica coated with SiMA $(9 \mathrm{~g})$ was degassed under nitrogen in dioxane (90 g). Azobisisobutyronitrile (AIBN) $(0.05 \mathrm{~g})$ was added as initiator. The copolymerisation time was $6 \mathrm{~h}$ at $60^{\circ} \mathrm{C}$. The final solution was poured into methanol, and the precipitated copolymer was isolated by filtration, dried at $30{ }^{\circ} \mathrm{C}$ for one night and at $65{ }^{\circ} \mathrm{C}$ under vacuum for $2 \mathrm{~h}$. ${ }^{1} \mathrm{H}-\mathrm{NMR}$ analysis in $\mathrm{CDCl}_{3}$ showed a molecular composition of 97.6 and $2.4 \mathrm{wt} \%$ for DMA and SiMA, respectively. TGA analysis showed that the corresponding DMA-SiMAsilica sample contained $90.6 \mathrm{wt} \%$ of stable materials at $600{ }^{\circ} \mathrm{C}$. In order to get an idea about the $M_{\mathrm{w}}$ of the coating copolymer, the apparent molecular weight was determined by size elution chromatography (SEC) in THF, using a PMMA standard calibration. Under the same conditions as noted above the apparent $M_{\mathrm{w}}$ was 80,000 and $M_{\mathrm{w}} / M_{\mathrm{n}} \cong 1.6-1.8$. But, one may assume that in the presence of silica, impurities are introduced into the system, which may decrease the $M_{\mathrm{w}}$ of the copolymer.

\subsection{Rheological measurements}

The viscoelastic properties of the gels were measured with a Rheometrics RSI ARES rheometer equipped with a force balance transducer. $3 \mathrm{~mm}$ thick samples with a $25 \mathrm{~mm}$ diameter were prepared for the temperature sweep experiments. They were tested in the shear mode with the parallel-plate geometry at $4{ }^{\circ} \mathrm{C} / \mathrm{min}$. The temperature control was accurate within $1{ }^{\circ} \mathrm{C}$. The applied strain $(1 \%)$ was such that the linear viscoelastic regime was maintained (1 Hz frequency).

\subsection{Synchrotron X-ray measurements}

Small-angle X-ray experiments were performed on the SAXS/WAXS beamline BM26 DUBBLE at the European Synchrotron Radiation Facility (ESRF, Grenoble) [49]. The radiation spectrum from the source was monochromatised using a double-crystal Si (111) monochromator with sagittal focusing on the second crystal to give an intense monochromatic X-ray beam in the range 5-30 keV with a transmission bandwidth of $\Delta \lambda / \lambda \approx 2 \times 10^{-3}$ and having a fixed exit height. The optical bench allowed a variable sample-to-detector distance of 1.0-7.0 m, covering a scattering vector $q$ from 0.005 to $0.15 \AA^{-1}$. The scattering vector was defined as $|\mathbf{q}|=q=(4 \pi / \lambda) \sin \theta$ with $\lambda$ the wavelength equalling $1.24 \AA$, and $2 \theta$ is the scattering angle. The beamline was equipped with a two-dimensional small-angle X-ray scattering (SAXS) detector based on gas filled wire chambers. Collagen was used as a standard for the calibration of the instrument. The SAXS data were normalised to the intensity of the primary beam and corrected for the detector response. For the preliminary reduction of SAXS data the software packages BSL [50] and FIT2D [51] were used. The samples were filled in circular brass sample holders, and a Peltier element allowed heating and/or cooling in the range from 20 to 140 ${ }^{\circ} \mathrm{C}$ at $2{ }^{\circ} \mathrm{C} / \mathrm{min}$ with a precision and temperature stability of $<0.1{ }^{\circ} \mathrm{C}$.

\subsection{Combined mechanical and small-angle neutron scattering experiments}

SANS measurements were performed on the SANS facility of the Risø National Laboratory using neutrons, monochromatised with a mechanical velocity selector, of a wavelength of $\lambda=0.94 \mathrm{~nm}$ and a full-width-half maximum $\mathrm{d} \lambda / \lambda=0.18$ using a sample-detector distance of $6 \mathrm{~m}$. The samples were mounted in a shear sandwich cell in a rheometrics RSA-2 modified for simultaneous measurements of dynamic mechanical and structural properties [52]. The sample thickness was $0.2 \mathrm{~mm}$. In this study a strain amplitude of $4 \%$ and a frequency of $1 \mathrm{rad} / \mathrm{s}$ were used throughout.

\section{Results and discussion}

\subsection{Morphology study}

Fig. 1 (curve A) shows a typical SAXS diffraction pattern for a neat PS-PEB-PS triblock copolymer gel. As extensively discussed elsewhere [21-23], the plot of $I(q)$ as a function of $q$ is dominated by the polystyrene micellar cores, and contains information on the corresponding structure factor and the form factor, respectively. The polystyrene form factor peaks, which result from intradomain interferences contain information on the size and shape of the polystyrene domains, whereas the structure factor peaks, which originate from the interdomain interference, provide information on the mutual arrangement of the polystyrene domains within the rubbery 
matrix. From the position $q^{*}$ of the first structure factor peak, the characteristic distance $D=2 \pi / q^{*}$ can be extracted. The characteristic distance of the neat triblock copolymer gel equals $315 \AA$.

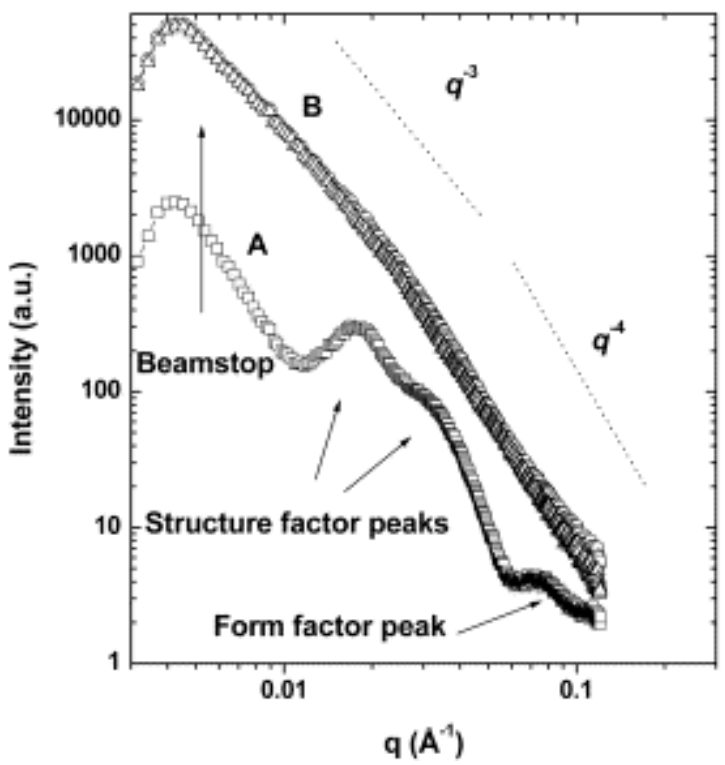

Fig. 1. Small-angle X-ray scattering pattern of a neat triblock copolymer gel (curve A, $\square$ ) and a triblock copolymer gel reinforced with $2.2 \mathrm{wt} \%$ hydrophilic silica (curve B, $\Delta$ ). Subtracting curve A from curve $B$ results in the curve marked with open circles. (The apparent peak at $0.004 A^{-1}$ is an artefact of the beamstop.)

The SAXS scattering profile reported for all the silica reinforced gels after quenching to room temperature (Fig. 1 curve $B, \Delta$ ), is basically independent of the type of silica and completely different from the profile of the native PS-PEB-PS gel. At very low $q$, the scattering intensity is increased by more than one order of magnitude. This effect is even more pronounced at higher silica content (not shown here). Therefore, the increased scattering intensity at the lower $q$-values results from silica particles that form rather large aggregates. The scattering pattern is characterised by two linear regimes in the log-log presentation (Fig. 1). At $q>0.02 \AA^{-1}$, the $q^{-4}$ dependence indicates large and smooth surface areas. For $q<0.02 \AA^{-1}$, the scattering intensity is $q^{-\alpha}$ dependent, with $\alpha$ slightly lower than 3 , in agreement with a relatively dense packing of the individual silica particles. The absence of the dominating structure factor peak observed for the neat SEBS gel might suggest that microphase separation and network formation cannot occur when the gel is mixed with $2.2 \mathrm{wt} \%$ of silica particles.

Nevertheless, the scattering intensity by the silica particles strongly dominates the polymer scattering as result of a large size and a large contrast factor for X-ray scattering, as discussed below. Indeed, data of curve A ( $\square$ ) have been subtracted from data of curve B $(\Delta)$, and the resulting curve ( $O$ in Fig. 1$)$ is essentially superimposed to curve $\mathrm{B}$, which explains that the triblock copolymer gel contribution goes unobserved.

Contrast factors for neutron scattering are significantly different from that of X-ray scattering, and the silicascattering contribution is not dominating the polymer contribution as in SAXS experiments. Fig. 2 shows the neutron scattering pattern for the neat and the reinforced silica gels. A broad, but distinct maximum in $I(q)$ $\left(0.013 \AA^{-1}<q<0.03 \AA^{-1}\right)$ indicates that the copolymer network is maintained after silica reinforcement. The broad maximum, which is observed for all the reinforced gels, can be accounted for by the heterogeneous distribution of the polystyrene nanophase domains within the reinforced SEBS gel. Last but not least, the elasticity of the gel persists in the presence of silica particles, which is a macroscopic evidence of network formation. The samples analysed in Fig. 1 and Fig. 2 were prepared by high temperature dissolution of SEBS in the Fina oil, followed by quenching below the glass transition temperature of polystyrene. Consequently, a non-equilibrium microphase separation is frozen in. In order to get more-detailed information on the structure-property relationships for the reinforced gels, dynamic mechanical and structural properties were recorded simultaneously as a function of temperature in a combined shear-SANS experiment. The heating rate of the samples was $10^{\circ} \mathrm{C} / \mathrm{min}$. The elastic and the loss moduli $\left(G^{\prime}\right.$ and $\left.G^{\prime \prime}\right)$ were measured with a shear amplitude of $4 \%$ and a frequency of $1 \mathrm{rad} / \mathrm{s}$. The scattering data were recorded every $2 \mathrm{~min}$. It must be noted that the data of the scattering curves collected under shear are values integrated over several shear periods and over a temperature range of $20^{\circ} \mathrm{C}$. Fig. 3 and Fig. 4 show the curves reported for a gel reinforced by $2.2 \mathrm{wt} \%$ of $\mathrm{SiO}_{2}-\mathrm{PDMS}$ and $\mathrm{SiO}_{2}$-hexyl, respectively. The neutron scattering pattern at room temperature consists of a broad maximum in the 0.012 and $0.028 \AA^{-1} q$-range and an increasing scattering at very low $q$. On heating from room temperature up to $80{ }^{\circ} \mathrm{C}$, no significant 
structural change is observed. Above $80{ }^{\circ} \mathrm{C}$, a relatively narrow peak starts to emerge at $0.016 \AA^{-1}$, which grows in intensity and is shifted to slightly higher $q$-values $\left(0.021 \AA^{-1}\right)$ when the temperature is increased up to $105^{\circ} \mathrm{C}$. The temperature dependence of the simultaneously recorded storage modulus $\left(G^{\prime}\right)$ and loss modulus $\left(G^{\prime \prime}\right)$ (Fig. 3 and Fig. 4), indicates that these structural changes occur in the plastic-fluid regime, thus when the polystyrene domains are soft enough for the applied stress to pull out polystyrene blocks from the nanodomains, which can accordingly reorganise themselves. The scattering pattern then shows one peak and a shoulder, which resembles the 'typical' scattering pattern observed for the PS-PEB-PS gels ( Fig. 1 curve A), reflecting the correlation between the polystyrene spheres. No change is observed in the small-angle term, consistent with the absence of macroscopic phase separation between silica and SEBS.

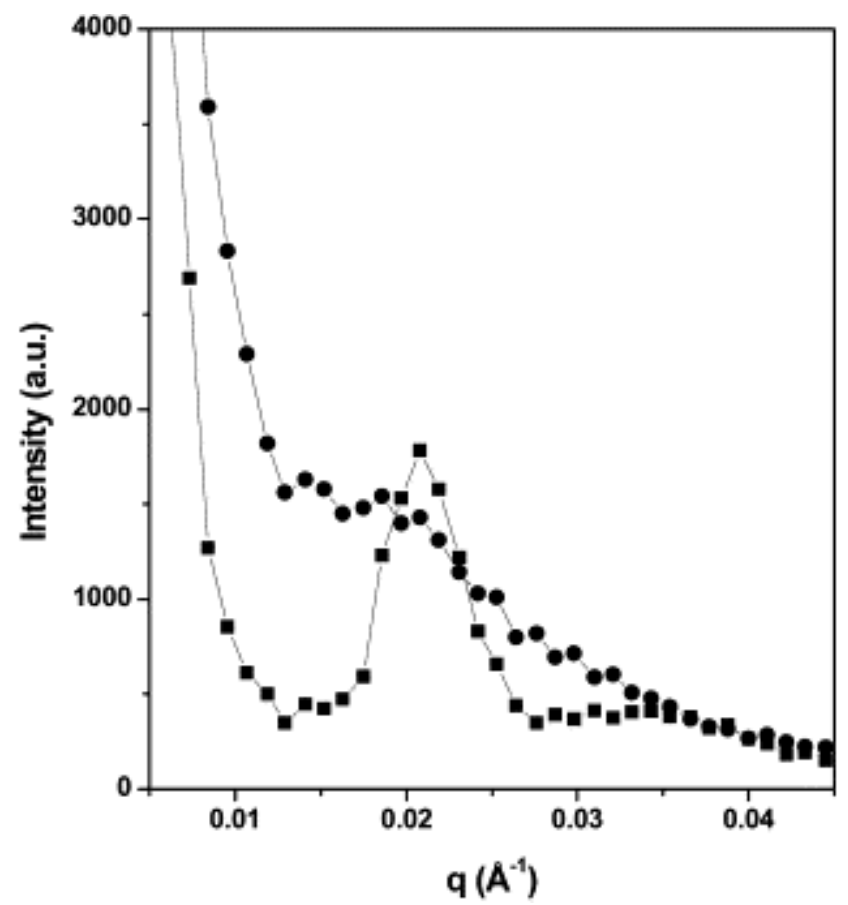

Fig. 2. Neutron scattering pattern of a neat triblock copolymer gel (•) and a triblock copolymer gel reinforced with 2.2 wt\% PDMS coated silica (•). 

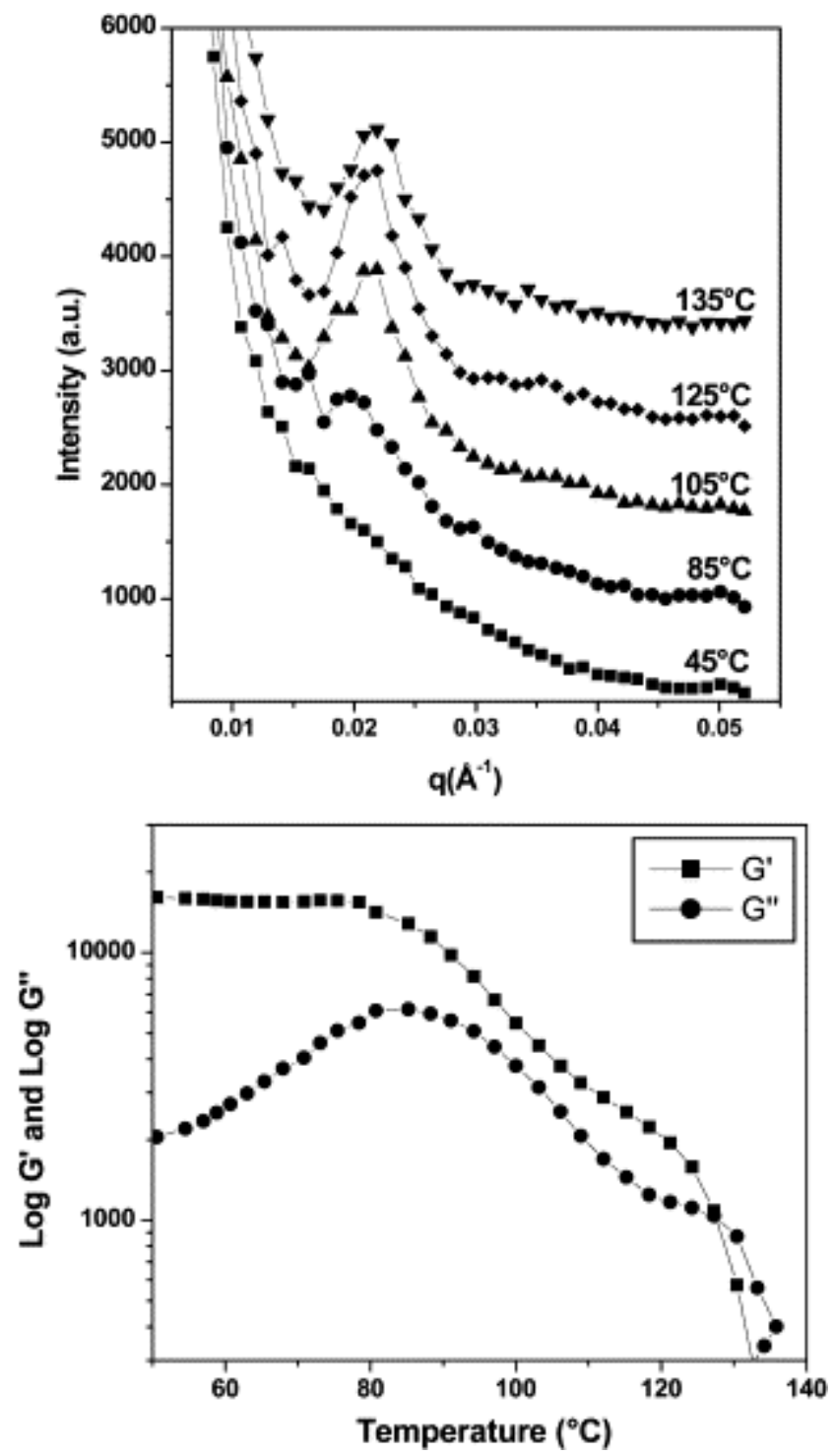

Fig. 3. (A) Temperature dependent SANS curves of a triblock copolymer gel reinforced with 2.2 wt\% PDMS coated silica. All curves are on the same scale, but vertically shifted for clarity. (B) Temperature dependence of the storage modulus $\left(G^{\prime}\right)$ and the loss modulus $\left(G^{\prime \prime}\right)$ recorded simultaneously with the neutron data. The heating rate of the sample was $10^{\circ} \mathrm{C} / \mathrm{min}$. 

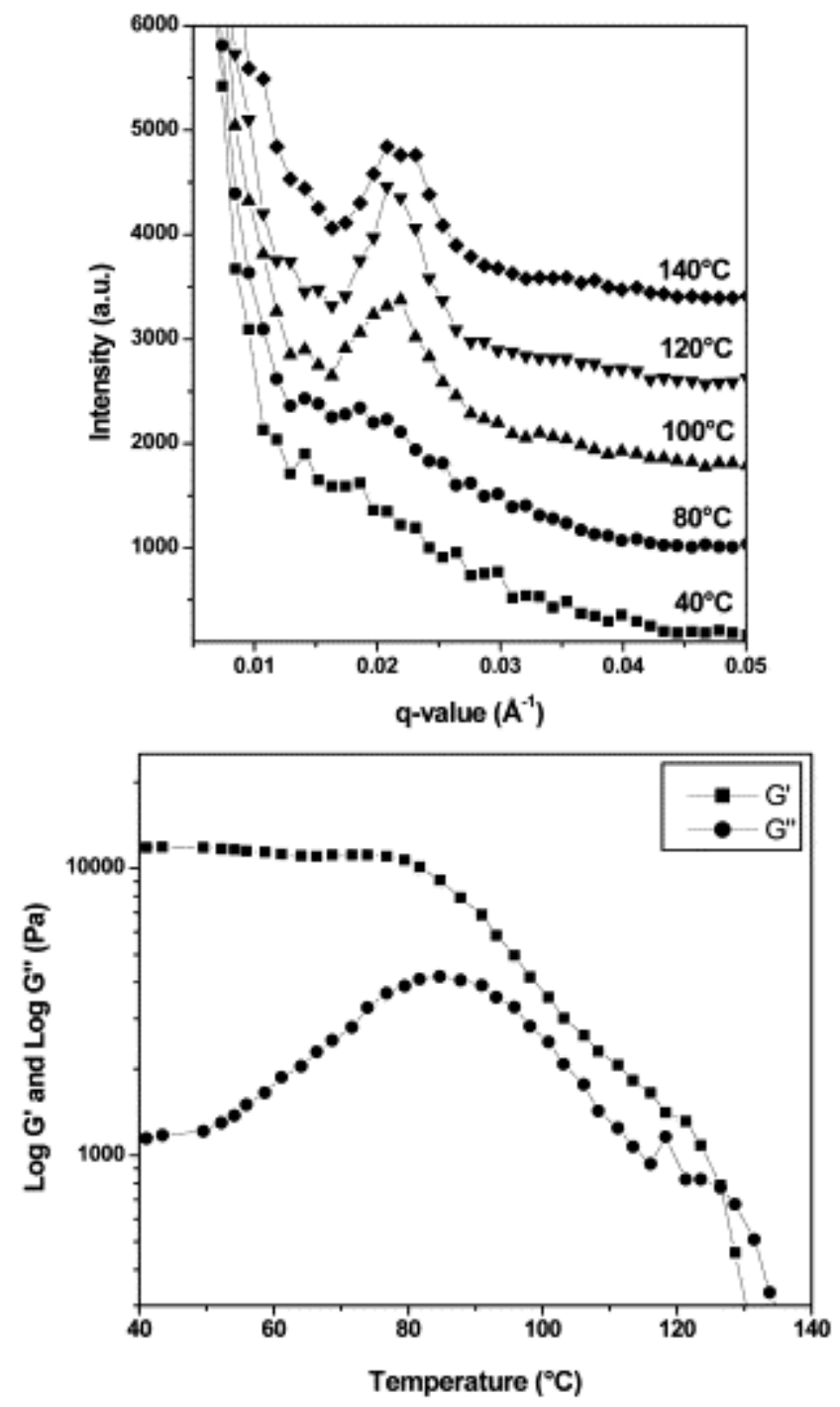

Fig. 4. (A) Temperature dependent SANS curves of a triblock copolymer gel reinforced with $2.2 \mathrm{wt} \%$ hexamethylene coated silica. All curves are on the same scale, but vertically shifted for clarity. (B) Temperature dependence of the storage modulus $\left(G^{\prime}\right)$ and the loss modulus $\left(G^{\prime \prime}\right)$ recorded simultaneously with the neutron data. The heating rate of the sample was $10^{\circ} \mathrm{C} / \mathrm{min}$.

The presence of silica particles in the system does not inhibit the nanophase separation of polystyrene, but their presence accelerates the gel formation. Indeed, the gel time measured at $106^{\circ} \mathrm{C}$ by rheology (i.e., the time at which the rheological phase shift, $\tan \delta$, is independent of frequency) is decreased as result of silica addition (Table 1). The random arrangement of polystyrene domains formed in the melt-mixed system is frozen in on cooling, resulting in the observed scattering pattern without clear structure factor information in the case of SANS and SAXS. 
Table 1. Comparison of the storage modulus, gel time, and the order-disorder transition of the different silica reinforced triblock copolymer gels

\begin{tabular}{|c|c|c|c|}
\hline System & $G^{\prime}(\mathrm{Pa})$ at $30^{\circ} \mathrm{C}$ & Gel time (s) at $106^{\circ} \mathrm{C}$ & $T_{\text {ODT }}\left({ }^{\circ} \mathrm{C}\right)^{1}$ \\
\hline $\begin{array}{l}\text { Unfilled triblock copoly- } \\
\text { mer gel }\end{array}$ & 18,000 & 4700 & 103 \\
\hline $\begin{array}{l}\mathrm{SiO}_{2}(\mathrm{OH}) \text { filled riblock } \\
\text { copolymer gel }\end{array}$ & 25.500 & 4100 & 105.5 \\
\hline $\begin{array}{l}\mathrm{SiO}_{2} \text { (PBd-TEOS) filled tri- } \\
\text { block copolymer gel }\end{array}$ & 32.700 & 3500 & 107 \\
\hline $\begin{array}{l}\mathrm{SiO}_{2} \text { (hexamethylene) filled } \\
\text { triblock copolymer gel }\end{array}$ & 37.500 & 2950 & 109 \\
\hline $\begin{array}{l}\mathrm{SiO}_{2} \text { (PDMS) filled riblock } \\
\text { copolymer gel }\end{array}$ & 32.000 & 1360 & 111 \\
\hline $\begin{array}{l}\mathrm{SiO}_{2} \text { (DMA/SiMA) filled } \\
\text { miblock copolymer gel }\end{array}$ & 29.500 & 300 & 120 \\
\hline
\end{tabular}

Time resolved synchrotron data (not shown) exhibit similar results (heating rate is $4{ }^{\circ} \mathrm{C} / \mathrm{min}$ ). No structure factor peak is observed, the scattering intensity is only increased at very low $q$ at room temperature. However, heating above $T_{\mathrm{g}}$ of polystyrene results in a scattering pattern, which is a combination of the strong scattering of the silica particles at very low $q$ and of a very weak correlation peak at $q=0.02 \AA$. Silica aggregates in the triblock copolymer gel clearly strongly affect the scattering of the gels. As it can be safely assumed that silica is selectively in the matrix of the gels, it appears that the X-ray phase contrast is rather small. Moreover, taking into account that the silica-coated particles are incompatible with PS and noticing that the peak of the form factor of the PS-domains is at the same position as for the native gel, it can indeed be concluded that the silica particles are confined to the matrix. In the case of neutron scattering the scattering ability of the material is largely independent of silica addition. Scattering patterns at $90{ }^{\circ} \mathrm{C}$ are compared in Fig. 5 for the neat gel and gels reinforced by a variety of silica particles. A very small shift in the position of the structure factor peak is observed for the unfilled gel as compared to the reinforced gels whatever silica used (Fig. 5). The very small reduction in intradomain distance between the polystyrene domains in the presence of silica can be explained by the role of the solvent. In the neat triblock copolymer gel, $81.5 \mathrm{wt} \%$ of solvent is associated with the midblock, resulting in a swollen state of the midblock. Replacing some amount of the solvent by silica, namely $2.2 \mathrm{wt} \%$, will result in a shorter interdomain distance between the polystyrene domains $[21 ; 23]$.

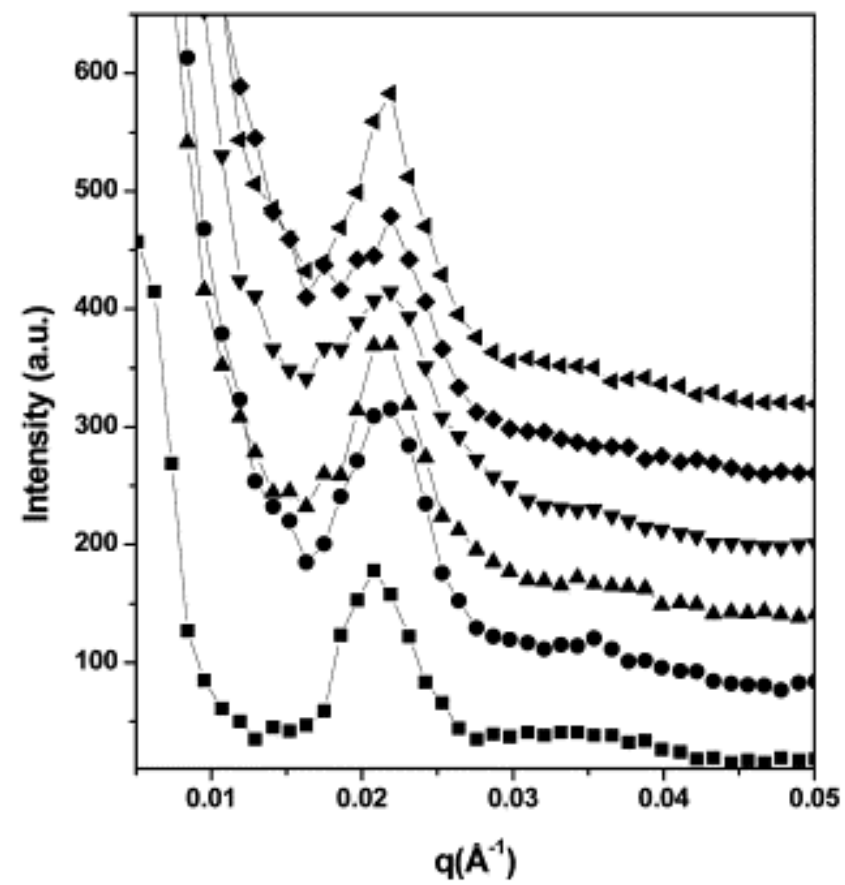

Fig. 5. Neutron scattering patterns at $90{ }^{\circ} \mathrm{C}$ of a neat triblock copolymer gel (-); a gel reinforced with 2.2 wt $\%$ PDMS coated silica (•); a gel reinforced with hexamethylene coated silica $(\boldsymbol{\Delta}) ;$ a gel reinforced with $2.2 \mathrm{wt} \%$ 
$D M A /$ SiMA coated silica $(\mathbf{\nabla})$; a gel reinforced with $2.2 \mathrm{wt} \%$ TEOS end-terminated silica ( $)$ and a gel
reinforced with $2.2 \mathrm{wt} \%$ hydrophilic silica $(\mathbf{4})$. For clarity, the patterns are displaced by an appropriate integer.

Heating from $105{ }^{\circ} \mathrm{C}$ up to $140{ }^{\circ} \mathrm{C}$ results in a continuous dissolution of the network and the polystyrene domains, as assessed by a regular decrease in peak intensity reflecting the micellar correlation and a concomitant increase in the structure factor line-width. The structure factor peak emerges again on cooling, whatever the reinforced gel under consideration. However, the temperature from which the intensity starts to decrease on heating is dependent of the silica particles used. Furthermore, the neutron scattering data are not sensitive enough to identify the order-disorder transition temperature $\left(T_{\mathrm{ODT}}\right)$ for the silica reinforced networks. Each scattering pattern results indeed from of a signal integration over a temperature range of $20^{\circ} \mathrm{C}$. SAXS measurements are not an alternative approach, because, as stated before, of a lack in contrast. Therefore, rheological measurements have been conducted.

\subsection{Rheological behaviour}

In order to correlate the rheological and morphological data, temperature sweeps were performed. Upon heating, the gels show a transition from a rubbery gel to a plastic fluid $\left(T_{\mathrm{P}}\right)$ and from a plastic fluid to a viscoelastic liquid $\left(T_{\mathrm{ODT}}\right)$, as exemplified by Fig. 3 and Fig. $4 . T_{\mathrm{ODT}}$ and the storage modulus at room temperature are presented in Table 1 . The $T_{\mathrm{P}}$ transition is characterised by a small decrease in the storage modulus and a rather broad maximum in loss modulus. The disordering of the network $\left(T_{\mathrm{ODT}}\right)$, on the other hand, sets-in at the crossover of $G^{\prime}$ and $G^{\prime \prime}$. Both transitions can be interpreted in terms of the stability of the microstructure of the system [3033]. In the plastic fluid regime, the polystyrene domains become softer and stress can cause the pullout of styrene blocks. The yield stress of this mechanism is determined by the mixing enthalpy of styrene and ethylene/butylene segments. Above the order-disorder temperature, the polystyrene phase is further swollen with solvent and also the segregation tendency between the different components is further reduced, resulting in a spontaneous polystyrene transfer between different microdomains by thermal motion. Nevertheless, the microphase-separated structure still exists, as evidenced by a weak structure factor signal attributed to the intermicellar correlation. All the silica reinforced gels show an increase in both transition temperatures and in the dynamic viscoelastic storage modulus observed at $30{ }^{\circ} \mathrm{C}$ ( Table 1 ).

Although the surface of the $\mathrm{SiO}_{2}-\mathrm{OH}$ particles is polar and not favourable to interaction with the oil phase, an increase in $G^{\prime}$ is observed upon filling the gel with $2.2 \mathrm{wt} \%$ of these particles. The observed increase of the storage modulus is due to the presence of the extra glassy domains (silica) able to absorb stress applied on the system. This effect is, however, enhanced whenever the silica surface is coated by hydrophobic chains, thus when the compatibility of the filler with the matrix is improved, resulting in a more homogeneous distribution of the inorganic component within the soft phase of the gel, inducing a better stress transfer between the different soft/hard phases. $\mathrm{SiO}_{2}-$ hexamethylene imparts the highest $G^{\prime}$ modulus to the gel $(37,500 \mathrm{~Pa})$, and $\mathrm{SiO}_{2}$ DMA/SiMA seems to be the less efficient modified silica. Actually, $G^{\prime}$ of the hydrophobic silica reinforced gels increases as follows: $\mathrm{SiO}_{2}-\mathrm{DMA} / \mathrm{SiMA}<\mathrm{SiO}_{2}-\mathrm{PDMS}<\mathrm{PBd}-\mathrm{TEOS}-\mathrm{SiO}_{2}<\mathrm{SiO}_{2}$-hexyl. The storage modulus of the triblock copolymer gel is proportional to the amount of glassy domains, PS domains and added silica particles. The weight percentage of silica added, is for all the different gels the same, namely $2.2 \mathrm{wt} \%$ and the total amount of coating groups in the silica particle is for the different silica's the same namely, $8.5 \mathrm{wt} \%$. Therefore, one could presume the storage modulus to be identical for all the samples. However, the highest value of $G^{\prime}$ is observed for the physical gel reinforced with the shortest coating group (hexamethylene). The other coating groups are polymers with for example a molar mass of 80,000 for SiMA of the DMA/SiMA coating copolymer and of 3700 for the molar mass of polybutadiene of the PBd-TEOS coating group. As confirmed by the manufacturer, PDMS is an oligomeric coating with a $M_{\mathrm{w}}$ higher than hexamethylene. Thus, the length of the coating groups decreases in the series DMA/SiMA $>$ PB-TEOS $\cong \mathrm{PDMS}>$ hexamethylene. It is not surprising that low molecular weight coating groups are more efficient, because at a constant weight percent of organic groups at the surface of silica $(8.5 \mathrm{wt} \%)$, the grafting density is as high as the molecular weight of these groups is low. In the case of high molecular weight, long coating chains dangle in the soft phase of the gel, giving rise to areas on the surface of the silica particle, which are not shielded by the coating. This will result in a decrease of $G^{\prime}$ compared to the storage modulus of the gel reinforced with hexamethylene coated silica.

As mentioned above, the order-disorder transition sets-in when the polystyrene blocks become soft enough so that PS chains can transfer between different hard micro-domains by thermal motion. Thus, any additives increasing the enthalpic and/or entropic interactions between the different components of the system and inhibiting such thermal movements support the stability of the PS domains. An increase by $2.5^{\circ} \mathrm{C}$ is observed in case of $\mathrm{SiO}_{2}-\mathrm{OH}$ and by $4-8{ }^{\circ} \mathrm{C}$ when silica is modified by a hydrophobic coating, i.e. $\mathrm{PBd}$, hexyl and PDMS 
grafts. The shift of the disordering temperature of the network to higher temperatures is highest for the DMA/SiMA end-capped silica. Since DMA/SiMA system is not the most efficient one to increase the modulus and, since the ability of the coating groups to interact increases from hexamethylene to PBd-TEOS, over PDMS and finally to the DMA/SiMA copolymer, one can argue that the $T_{\mathrm{ODT}}$ of the gel network is increased, not due to the compatibility between the silica particles and the matrix of the gel, but rather due to stronger interactions and entanglements of the coating groups with the soft phase as the molar mass of the coating group increases. The PBd-TEOS coated silica reinforced sample does not follow this trend, considering the low molar mass of the hexamethylene coating group. However, the reverse is observed. This diverging behaviour is probably due to the presence of some unreacted tetraethyl orthosilicate (TEOS) acting as a plasticiser for the polystyrene domains.

The gel reinforced by the $\mathrm{SiO}_{2}$-DMA/SiMA particles exhibits a very significant increase in $T_{\mathrm{ODT}}$, i.e. $17^{\circ} \mathrm{C}$ compared with the neat gel and $9{ }^{\circ} \mathrm{C}$ with respect to the gel reinforced by PDMS-coated silica (Table 1). In addition to a high molar mass, the SiMA comonomer units can participate in condensation reactions in the presence of water, which might lead to a network of silica particles. This behaviour is indirectly supported by an increase in $G^{\prime}$ at room temperature, when the temperature sweep is repeated. Because $G^{\prime}$ at $25{ }^{\circ} \mathrm{C}$ remains constant when the same experiment is carried out for all the other gels analysed in this study, it may be concluded that the condensation of the SiMA groups is fast at high temperature and contributes to the interconnection of the silica particles. Since, all the other reinforced samples show no increase in the storage modulus after the first temperature sweep, one probably can rule out the effect of reorganisation of the polystyrene domains on the mechanical moduli; the increase in $G^{\prime}$ of the DMA/SiMA end-capped silica reinforced gels is clearly a unique feature of the SiMA-group.

The noticeable increase in $T_{\mathrm{ODT}}$ observed for the DMA/SiMA-silica reinforced sample is another consequence of the network of silica particles formed in the gel matrix. The silica particles, however, can only fulfil this function until the entanglements between the matrix and the silica network break-up and a viscous fluid is formed. It is known from the already reported combined SANS-rheological measurements (Fig. 3 and Fig. 4) that polystyrene domains are still present at these elevated temperatures (the structure factor maxima are still observed) and only start to disorder when tan $\delta$ equals 1 . Therefore the superposition of a chemical network onto the original physical network has a retarding effect on the disordering of the polystyrene domains as result of a loss in mobility of the chains. One can conclude that the order-disorder transition and the plastic fluid regime are strongly conditioned by the interaction between the midblock chain and the silica coating groups.

The rubber to plastic fluid transition $\left(T_{\mathrm{P}}\right)$ for the different types of silica reinforced triblock copolymer gels changes in a similar manner as $T_{\mathrm{ODT}}$, for the same reasons. The gel time (Table 1) on the other hand decreases in the latter sequence. The gel time, the time at which $\tan \delta$ becomes independent of frequency, is recorded at 106 ${ }^{\circ} \mathrm{C}$ after quenching the sample from the disordered state. The systematic decrease in gel time suggests that as the midblock interacts more favourably with the silica particles and their surface coating, the microphase separation of the PS increases and gel formation occurs earlier. Indeed, the gel time is the time needed for the material to behave as one single macromolecule under some shear rate. At this point, moduli are predicted [53-55] and experimentally observed to scale with the frequency $(f)$ according to the scaling exponent theory, where $G^{\prime}(\omega)=G^{\prime \prime}(\omega)=\omega^{\Delta}, \omega=2 \pi f$ and $\Delta$ is the scaling exponent $[53 ; 56-57]$. In addition, tan $\delta$ shows at the gel time a universal constant value $(\delta=\Delta(\pi / 2))$ [56]. One may assume that adding silica increases the amount of hard knots and the gel may reach some mechanical properties faster. This phenomenon is more pronounced when additional entanglements and/or interaction precursor are added. A complete rheological study will be presented in a forthcoming paper.

The compatibility influences also the rubber to plastic fluid transition. Actually, this transition limits potential applications of these PS-PEB-PS triblock copolymer gels to relative low temperatures (utility limit around 70 ${ }^{\circ} \mathrm{C}$ for gels based on low molar mass materials). But, in the presence of silica and due to the increased compatibility between silica and the matrix, $T_{\mathrm{P}}$ increases, i.e. $8^{\circ} \mathrm{C}$ in case of the DMA/SiMA silica reinforced gel compared to the transition temperature of the neat triblock copolymer gel. Hence this type of studies and the present observation can open the way for new high temperature applications.

\section{Conclusions}

Comparing different types of silica coating groups reveals that the effectiveness of such systems to improve the SEBS gel high temperature performance is strongly related to the compatibility of the inorganic particles and the gel-matrix. The higher the compatibility between silica and the midblock chains the stronger the different gel 
parameters are influenced: $T_{\mathrm{P}}$ and $T_{\mathrm{ODT}}$ increase, and the gel time decreases drastically when silicas are used with hydrophobic, high molar mass coating groups.

The gels are significantly reinforced by the presence of silica particles in the rubbery matrix. But in contrast to the transition temperatures, the storage modulus at room temperature is influenced in a somewhat different way by the molar mass of the hydrophobic coating groups. Short coating groups have a higher coating ability than longer coating groups. The presence of any type of silica clustered in rather large aggregates in the triblock copolymer gel prohibits on gelsetting the regular ordering of the polystyrene domains. The latter ordering emerges in any case on heating.

Although, the presence of silica disrupts the regular ordering of the microdomains, the triblock copolymers are mechanically strengthened; the gel formation proceeds faster and $T_{\mathrm{ODT}}$ and $T_{\mathrm{P}}$ are increased when a reinforcing agent, in the present case silica, is added to the gel system. The positive influence on the transition temperature from a viscoelastic rubber to a plastic fluid is the most important feature induced by the presence of silica in the triblock copolymer gel, an observation, which can be helpful to widen the applicability of these types of low molar mass triblock copolymer gels into a higher temperature regime. The gel reinforced with a silica endterminated with a moisture-curable group shows the strongest increase in transition temperatures, resulting in a most promising system to extent the use of polystyrene-polyethylene/polybutylene-polystyrene triblock copolymer gels towards higher temperature applications.

\section{Acknowledgements}

This research was supported by the Flemish Institute for the Promotion of Scientific-Technological Research in Industry (IWT). The authors are indebted to Tyco Electronics Raychem N.V. (former Raychem N.V.) for financial support. E.T. is grateful to the National Fund for Scientific Research (FWO) for a research position. The work was supported by the EU program for Large scale Facilities. E.T and H.R. are indebted to the DUBBLE-team (ESRF, Grenoble) for experimental support. S.A. and R.J. are grateful to the 'Services Fédéraux des Affaires Scientifiques, Techniques et Culturelles' for support in the frame of the PAI 4/11 'Supramolecular Chemistry and Supra-molecular Catalysis'.

\section{References}

[1] Polizzi S, Stribeck N, Zachmann HG, Bordeanu R. Colloid Polym Sci 1989;267:281-91.

[2] Florenzier LS, Torkelson JM. Macromolecules 1992;25:735-42.

[3] Mortensen K. Curr Opin Colloid Interface Sci 1998;3:12-19.

[4] Mortensen K, Pedersen JS. Macromolecules 1993;26:805-12.

[5] Mortensen K. Macromolecules 1997;30:503-7.

[6] Yu JM, Teyssié Ph, Jérôme R. Polymer 1997;38:347-54.

[7] Yu JM, Teyssié Ph, Blacher S, Brouers F, L'Homme G, Jérôme R. Macromolecules 1996;29:5384-91.

[8] Yu JM, Jérôme R. Macromolecules 1996;29:8371-8.

[9] Yu JM, Blacher S, Brouers F, L'Homme G, Jérome R. Macromolecules 1997;30:4619-25.

[10] BalsaraNP, Tirrell M, Lodge TP. Macromolecules 1991;24:1975-86.

[11] Hamley IW, Fairclough JPA, Ryan AJ, Gleeson AJ, Pedersen JP, Ryu CY, Lodge TP. Macromolecules 1998;31:1188-96.

[12] Jeon B, Bae YH, Kim SW. Macromolecules 1999;32:7064-9.

[13] Ples`til J, Hlavata' D, Hrouz J, Tuzar Z. Polymer 1990;31:2112-7.

[14] Fleischer G, Kon`a'k C`2, Puhlmann A, Rittig F, Ka“rger J. Macromolecules 2000;33:7066-71.

[15] Holmqvist P, Alexandridis P, Lindman B. Langmuir 1997;13: 2471-9.

[16] Raspaud E, Lairez D, Adam M, Carton JP. Macromolecules 1994;27: 2956-64.

[17] Raspaud E, Lairez D, Adam M, Carton JP. Macromolecules 1996;29: 1269-77.

[18] Prasman E, Thomas EL. J Polym Sci, Polym Phys 1998;36:1625-36.

[19] Quintana JR, Diaz E, Katime I. Polymer 1998;39:3029-34.

[20] Quintana JR, Jã̃̃ez MD, Hernã ez E, Garc1'a A, Katime I. Macromolecules 1998;31:6865-70.

[21] Mischenko N, Reynders K, Mortensen K, Scherrenberg R, Fontaine F, Graulus R, Reynaers H. Macromolecules 1994;27:2345-7.

[22] Mischenko N, Reynders K, Koch MHJ, Mortensen K, Pedersen JS, Fontaine F, Graulus R, Reynaers H. Macromolecules 1995;28:

2053-62.

[23] Reynders K, Mischenko N, Kleppinger R, Mortensen K, Koch MHJ, Reynaers H. J Appl Crystallogr 1997;30:684-9.

[24] Kleppinger R, Reynders K, Mischenko N, Overbergh N, Koch MHJ, Mortensen K, Reynaers H. Macromolecules 1997;30:7008-11.

[25] Kleppinger R, Mischenko N, Theunissen E, Koch MHJ, Almdal K, Mortensen K, Reynaers H. Macromolecules 1997;30:7012-4.

[26] Kleppinger R, Mischenko N, Koch MHJ, Reynaers H. J Polym Sci, Polym Phys 1999;37:1833-40.

[27] Laurer JH, Bukovnik R, Spontak RJ. Macromolecules 1996;29: 5760-2.

[28] Laurer JH, Mulling JF, Khan SA, Spontak RJ, Bukovnik R. J Polym Sci, Polym Phys 1998;36:2379-91.

[29] Laurer JH, Mulling JF, Khan SA, Spontak RJ, Lin JS, Bukovnik R. J Polym Sci, Polym Phys 1998;36:2531-2.

[30] Watanabe H, Kuwahara S, Kotaka T. J Rheol 1984;28:393-409.

[31] Watanabe H, Sato T, Osaki K, Yao M, Yamagishi A. Macromolecules 1997;30:5877-92.

[32] Sato T, Watanabe H, Osaki K. Macromolecules 1996;29:6231-9.

[33] De Rosa ME, Winter HH. Rheol Acta 1994;33:220-37. 
[34] Soenen H, Liskova A, Winter HH, Overbergh N, Berghmans H. Polymer 1997;22:5653-60.

[35] Stone VW, Jonas AM, Legras R, Dubois P, Jérôme R. J Polym Sci, Polym Chem 1999;37:233-44.

[36] Iyengar DR, Perutz SM, Dai C, Ober CK, Kramer EJ. Macromolecules 1996;29:1229-34.

[37] Wang SM, Tsiang RCC. J Polym Sci, Polym Chem 1996;34: 1483-91.

[38] Gehlsen MD, Bates FS. Macromolecules 1994;27:3611-8.

[39] Kimishima I, Jinnai H, Hashimoto T. Macromolecules 1999;32: 2585-96.

[40] Adams JL, Quiram DJ, Graessley WW, Register RA, Marchand GR. Macromolecules 1998;31:201-4.

[41] Ren Y, Hillmyer MA, Lodge TP. Macromolecules 2000;33:866-76.

[42] Fetters LJ, Morton M. Macromolecules 1969;2:453-8.

[43] Soum A, Fontanille A, Aboudalle A. Polymer 1988;29:1528-34.

[44] Quirk RP. Polym Prep 1985;26:14.

[45] Yu JM, Dubois Ph, Teyssie Ph, Jero^me R. Macromolecules 1996;29: 6090-9.

[46] Weiss RA, Sen A, Willis CL, Pottick LA. Polymer 1991;32:1867-74.

[47] Weiss RA, Sen A, Willis CL, Pottick LA. Polymer 1991;32:2785-92.

[48] WO 8800603,1987, Raychem Ltd, invs.: Francis JV, Overbergh NM, Vansant J, Vansant JL. Chem Abstr 109: 74608w.

[49] Bras W. J Macromol Sci-Phys 1998; B37:557-65.

[50] Mant GR, Daresbury Laboratory, Private communication.

[51] Hammersley A, ESRF, Grenoble, Private communication.

[52] Hamley IW, Pople JA, Fairclough JPA, Terill NJ, Ryan AJ, Booth C, Yu G-E, Diat O, Almdal K, Vigild M, Mortensen K. J Chem Phys 1998;108:6929-36.

[53] Hess W, Vilgis TA, Winter HH. Macromolecules 1988; 21:2356.

[54] Martin JE, Adolf D, Wilcox JP. Phys Rev A 1989; 39:1325.

[55] Rubinstein M, Colby RH, Gillmor JR. Polym Prep (Am Chem Soc, Div Polym Chem) 1989;30(1):81.

[56] Chambon F, Winter HH. J Rheol 1987; 31:683.

[57] Winter H, Chambon FJ. J Rheol 1986; 30:367. 